\title{
Thriving from Challenges Stress: The Interactive Effect of Role Conflict, Time Pressure, and Negative Affect on Chinese Employees' Work Engagement
}

\author{
Mr. Christophe RUKUNDO ${ }^{1}$, Dr Jean-Noel BEKA BE NGUEMA ${ }^{1}$, Miss Cynthia \\ Atamba ${ }^{1}$, Miss Mohamed Habuba Halima ${ }^{1}$, Miss Akorfa Neku ${ }^{1}$ \\ ${ }^{1}$ University of Science and Technology of China, No.96, JinZhai Road Baohe District, \\ Hefei, Anhui, 230026, P.R. China. E-mail: chris3@mail.ustc.edu.cn
}

Received: Oct. 22, $2020 \quad$ Accepted: Nov. 16, 2020 Online published: Nov. 24, 2020

doi:10.5296/ijhrs.v10i4.17989 URL: https://doi.org/10.5296/ijhrs.v10i4.17989

\begin{abstract}
The present study examines role conflict as a hindrance stressor that influences how employees stay engaged in their work roles. The proposition is that two occupational stressors interact to impact work engagement via negative affect. Cross-sectional data were collected from working professionals pursuing an Executive MBA at a larger university in China to test the proposed model. Results from our field study $(N=237)$ revealed role conflict and time pressure as predictors of employees' negative affect. Also, results reveal that time pressure moderated the association between role conflict and employees' negative affect. These findings imply that two divergent occupational stressors can influence employee work-related outcomes. We concluded by discussing theoretical and practical implications.
\end{abstract}

Keywords: affect, role conflict, time pressure, work engagement, challenge-hindrance stress model, challenge stressors

\section{Introduction}

In the conceptualization of occupational stress, the usual predictor variables are stressors, which are characteristics or events in the workplace that can influence employee work engagement (McGrath \& Beehr, 1990; O’Brien \& Beehr, 2019). There are numerous potential stressors in the workplace that examining their categories would benefit researchers and practitioners alike. If stressors in a single category have similar effects on employees, we do not have to know as much about each stressor's effects independently. Through 
challenge-hindrance stress model dichotomy, researchers have explored when and how these occupational stressors influence work-related outcomes. The recent meta-analysis of challenge-hindrance model of stress conducted by Mazzola \& Disselhorst (2019) generally provides a useful distinction of occupational stressors for research and practice. Based on the challenge-hindrance stress model framework, we propose that time pressure as a challenge stressor buffers the negative effect of role conflict on employee work engagement through negative affect. The challenge-hindrance stress model framework states that all hindrance stressors consume energy, thwart personal growth, and hinder goal achievement (Kim \& Beehr, 2018). In contrast, challenge stressors have the potential to motivate and contribute to employee work engagement. Using this framework, we propose that high challenge stressors (i.e., time pressures) modulate hindrance stressors (i.e., role conflict) on employee negative affect.

This article makes three contributions to literature. First, by examining both time pressure and role conflict, this article measures the potential for within-person variation in negative affect during the appraisal of these stressors. Secondly, previous research combines all stressors or uses them interchangeably without examining how distinct they are from each other. In the current study, we propose that differentiating time pressure (challenge stressor) and role conflict (hindrance stressor) is a useful distinction, as these two may not be appraised as the same (Wu et al., 2019). Additionally, rather than looking at the broad categories of challenge (and hindrance) stressors (Tadić et al., 2015) in the present study, we decided to examine specific stressors (i.e., role conflict and time pressure) and see how they can affect employees' work engagement.

We propose that individual employee's appraisals of stressors as challenging may buffer the effect of hindrance stressors on negative affect (Rosen et al., 2020). Previous research, including meta-analyses, has usually started with assigning the different stressors as primarily hindrances or challenges (Olafsen \& Frølund, 2018). However, limited research has examined challenge stressors as a boundary condition. Researchers' assignments of stressors into categories are correct. However, it has failed to highlight the benefits of challenging stressors over hindrance stressors (Prem et al., 2017). In the current study, we examine how time pressure may buffer the negative effect of role conflict on employee negative affect and work engagement.

Moreover, the current study aims to contribute to the literature examining the relationship between challenge and hindrance stressors and the probable mechanisms underlying these associations. This study projected four hypotheses to test these relationships. These hypotheses included: (1) role conflict negatively predicts work engagement; (2) time pressure positively predicts work engagement; (3a) negative affect mediates the relationship between role conflict and work engagement; (3b) negative affect mediates the relationship between time pressure and work engagement; (4) time pressure moderates the relationship between role conflict and negative affect, such that the outcome is weaker when time pressure is high rather than low. 


\section{Challenge-Hindrance Stress Model}

There has been a growing research body on the challenge-hindrance stress model over the last decade and a half that attracted practitioners in an attempt to expand it. The study conducted by Mazzola \& Disselhors (2019) indicated that people would be more likely to appraise stressors differently, based on several external and internal variables. He continued to expand his study that challenge stressors offer an opportunity to solve challenges, which may enhance short-term achievements that lead to increased motivation, and even help an employee experience positive moods such as alertness, interest, and joy. Nevertheless, they also require resources, energy, and efficient coping strategy, leading to probable adverse psychological and physical outcomes. In this regard, we are more interested in testing our model and examining if Chinese employees can ultimately cope with the challenging stressors they face at the workplace to thrive in their careers. Theorists and researchers have long tried to evaluate stressors' interactions with environmental and personal characteristics in forecasting strains and other outcomes. In this regard, it is more likely that there is evidence that associations or moderating effects can occur. Still, the results are not always consistent, given the environment you are conducting your study.

The question for a challenge-hindrance typology is to know if environmental variables such as social support and job control can eventually moderate the association between stressors and outcomes differently, in a systematic way, for hindrance versus challenge stressors (O'Brien \& Beehr, 2019). The potential problem within the typology of challenge hindrance stress model is to know if different organizations and employees can equally respond to it, which we are unsure about it. More so, conditions or stressful job events can alter employees' well-being through tiredness, burnout, and illness. Therefore, this may not elucidate occupation stress in human employees entirely, yet, because not all stressors are the same or alike, and not all individuals react to the same stressors or stressful events after work is done. Therefore, our present study aims to utilize an environmental moderator of time pressure and see how it can ultimately affect Chinese employees' work engagement. Unlike hindrance stressors linked with fear, sadness, and anxiety, challenge stressors can stimulate positive emotions such as happiness and satisfaction, leading to employees' motivation. Subsequently, working individuals will be in an active working state when involved in a challenge-stressors style, leading to a greater work engagement. This positive psychological state helps motivate employees' spirit at work (Lin et al., 2020).

\section{Hypothesis Development}

\section{Role conflict negatively predicts work engagement}

Work engagement will always be an essential factor for both organizations and employees to achieve their goals. We know that without employees, there is no organization and without organizations, there are no employees. That is why in our existing study, we are very much concerned about how work engagement can always be sustained as the key for employees to thrive in their careers. Theoretically, work engagement is a critical factor in examining Greenhaus \& Powell's (2006) theoretical recommendations. Work engagement is explained as a positive, fulfilling work-related state of mind that is indicated by absorption, dedication, 
and vigor (Bakker et al., 2008; Schaufeli et al., 2002). Vigor is linked to high levels of energy while working. Dedication is related to being strongly involved in one's work and feeling a sense of challenge, pride, inspiration, enthusiasm, and significance. Lastly, absorption designates that one is fully focused and happily engrossed in one's work, whereby time passes fast. From the effect viewpoint, workers with high work engagement should coincide with cognition and positive affect, as they feel vigorous and work on meaningful responsibilities. Additionally, when people are entirely focused, they tend to feel time passes rapidly, which is a characteristic of a positive experience. From a performance viewpoint, individuals with high work engagement feel a strong sense of identity with their job, and they perceive their work as challenging, inspirational and meaningful; hence, they tend to knowledge transfer and utilize skills and resources to a greater extent at work (Bakker \& Demerouti, 2007).

According to the challenge - hindrance framework, the degree to which employees are energetic, enthusiastic about their work, and highly concentrated on their work (i.e., engaged) is greatly affected by the work environment (Cavanaugh et al., 2000). Specifically, the challenge-hindrance framework distinguishes two categories of occupational stressors; challenge stressors and hindrance stressors. In his proposed model, he showed that challenge stressors were work-related demands or circumstances that were potentially stressful but were bound to benefit employees at the workplace. These gains would either be intrinsic (e.g., satisfaction) or aligned to work achievements (e.g., learning and development). The most common challenge stressor is time pressure.

On the one hand, he stated explicitly that challenge stressors result in a resource gain, emphasizing the positive outcomes of challenge stressors. On the other hand, Cavanaugh et al. (2000) defined hindrance stressors as work-related demands or circumstances that constrained or interfered with employee work achievements and did not provide employees with intrinsic gains. Hindrances are considered an unmitigated source of stress because no significant gains offset the resources expended.

Research shows that challenge-hindrance framework adequately provided evidence for replication and generalizability (Bennett et al., 2018; Breevaart \& Bakker, 2018; Prem et al., 2017). For example, in one meta-analysis, raters coded various stressors as either challenge or hindrance; these challenges and hindrances related to strains, motivation, and performance. Nahrgang et al.'s (2011) meta-analysis using similar categorization of challenge and hindrance stressors showed that both related to burnout, engagement, job satisfaction, commitment, turnover intentions, and withdrawal behaviors. Finally, O'Brien and Beehr (2019) showed that challenge and hindrance stressors are related to moods and emotions that individuals display before and after work.

Previous research has found inconsistencies in the relationship between role conflict and work engagement. The challenge stressor- hindrance stressor framework (Abbas \& Raja, 2019) provides a possible explanation for the inconsistent findings regarding the link between hindrance stressors and employees' work engagement. Accordingly, some hindrance stressors such as role-conflict are obstacles toward goal achievement and personal learning that demotivate employees to engage in their work. Steed et al. (2019) found that role conflict was 
negatively related to employee work engagement in their meta-analysis. Accordingly, our hypothesis states:

Hypothesis 1: Role conflict negatively predicts work engagement.

\section{Time pressure positively predicts work engagement}

Challenge demands appear to have the potential to increase favorable states in employees (e.g., employee resilience). A recent daily diary study by Prem and colleagues (2017) provided clues about challenging stressors' had favorable outcomes. It focused on the favorable outcomes of time pressure on thriving and employees' appraisals of stressors. According to Gerich (2017) challenge - the hindrance stressor framework challenges stressors such as time pressure, brought a sense of accomplishment to employees who met their targets under extreme conditions. In support of this challenge, stressor- hindrance stressor distinction, Nahrgang et al. (2011) meta-analytically showed that time pressure was positively related to employee work engagement.

Further, Prem (2017) carried out a daily diary study among teachers that showed that they experienced self-concordant work motivation when they experienced challenging stressors compared to those days they experienced hindrance stressors. Tadić et al. (2015) found a similar pattern in their daily diary study among schoolteachers, showing that time pressure was positively related to employees' positive affect and work engagement. Accordingly, our hypothesis states:

\section{Hypothesis 2: Time pressure positively predicts work engagement.}

\section{Negative affect as a mediator}

Past theoretical and empirical work has examined the associations between affectivity and work-related outcomes (Deng et al., 2016), such as work engagement. According to Schwarz \& Clore (2006), people typically rely on their affect balance to form judgments of how (dis)contented they are with their work accomplishments. Prior research has confirmed a negative correlation between negative affect and work engagement (Schmitt et al., 2015), more so in the face of occupational stressors.

As challenge and hindrance stressors emerge from individual perceptions of events, these perceptions may influence the experience of negative affect and work engagement (Extremera \& Rey, 2016). While challenge stressors such as time pressure may reduce negative affect, hindrance stressors such as role conflict may increase negative affect and influence employee work engagement. Accumulating research literature has confirmed the mediator role of negative affect between self-reported stressors and work engagement both in organizational contexts (Tadić et al., 2015). Challenges stressors highlight personal growth potential, which increases positive affective responses and reduces negative affective responses (Parker et al., 2017). Contrary to challenge stressors, hindrance stressors, including role conflict, are associated with high negative affect. Furthermore, hindrance stressors represent strains, and therefore, overcoming them makes results acceptable rather than 
outstanding performance. Accordingly, our hypothesis states:

Hypothesis 3 (a): Negative affect mediates the relationship between role conflict and work engagement.

Hypothesis 3 (b): Negative affect mediates the relationship between time pressure and work engagement.

\section{Time pressure as a moderator}

Researchers and theorists have long attempted to examine stressors with personal and environmental characteristics in predicting strains and other outcomes. There is evidence that interactions or moderating effects can occur, but the results are not always consistent. A challenge-hindrance typology is whether challenge stressors can moderate the relationship between hindrance stressors and outcomes differently. Previous research has highlighted that overcoming challenges is why challenge stressors can have more favorable outcomes than hindrance stressors (Baer \& Oldham, 2006; 2000; Schmitt et al., 2015).

Challenging stressors such as time pressure buffer the effects of hindrance stressors on negative affect (Deng et al., 2016; Schmitt et al., 2015). Employees feel less negative affect when faced with role conflict on days when they have high (vs. low) time pressure. For instance, previous studies have shown that when employees receive negative feedback on a strict deadline, they are more likely to be more efficient and effective. Building on this knowledge, we examine the interactive effect of challenge stressors (i.e., role conflict) and hindrance stressors (i.e., role conflict) on employees' negative affect. We posit that even when employees face hindrance stressors such as role conflict, which may deplete their energy, conceiving the time required to finish the task (time pressure) may minimize employee's negative affect. Accomplishing a task in a short time may reframe the employee's perception of role conflict as an opportunity to learn and demonstrate competence (i.e., become challenging). Accordingly, our hypothesis states:

Hypothesis 4: Time pressure moderates the positive relationship between role conflict and negative affect such that this relationship is weaker when employee time pressure is high (vs. low).

\section{Participants}

The sample comprises 268 Executive MBA students from one of the largest Chinese universities who voluntarily participated in the survey. These students were full-time employees who studied on a part-time basis (during weekends).

\section{Recruitment}

Participants were recruited via student network WeChat groups. WeChat is a social media application that was developed by Tencent. WeChat was launched in 2011. Similar to WhatsApp and Telegram, WeChat has become the most popular social media platform in China. 


\section{Sample Selection}

We collected data from working Executive MBA students undertaking their studies on a part-time basis. We picked this sample for various reasons. First, working Executive MBA students emerge from a wide selection of organizations, which improved our generalizability findings. Second, previous research has revealed that working Executive MBA students have common factors such as relative income, job level, social class relevant to our study outcome. Third, working Executive MBA students met the criteria for being knowledgeable workers. Davenport $(2005 ; 19)$ specified that knowledge employees had higher expertise, education, or experience. Their jobs' primary purpose is to promote the creation, distribution, or application of knowledge compared to other workers. In this context, we assumed that knowledge workers were passionate about learning and development in their workplace and were able to work in high conflict environments. Also, previous research has shown that knowledge workers were susceptible to occupational stressors (Prem et al., 2017) and strived to be engaged in their work roles.

\section{Measures}

All scale items were decoded from English into Chinese and then back-translated into English to confirm their meaning. All the study variables were measured on 7-point Likert scales (e.g., $1=$ Strongly disagree; $7=$ Strongly agree).

Role Conflict: We used eight items from Perrewe's (2004) role conflict scale for our study. Sample items included, "I must do things that I think should be done differently" and, "I work under incompatible policies and guidelines." These items have been used in similar studies (Sonnentag, 2018).

Time pressure: We used five items from LePine's (2004) challenge stress scale and one item from Sonnentag (2003) time pressure scale. Representative items included, "How often do you work under time pressure?" and "Do you experience time pressure when you are required to complete your assignments?" These items have been used in similar studies (Sonnentag \& Zijlstra, 2006).

Negative Affect: We measured negative employee effect using Monin's (2008) 10-items scale. Sample items were "When faced with this experience, I feel fatigued" and "I feel bothered."

Work engagement: We measured work engagement using five-items from Bledow's (2011) scale. The sample item included "I feel strong and vigorous in my work" and "At my work, I feel bursting with energy."

Control Variables: We controlled gender, age, and tenure, as they have been shown to influence employee work engagement (Bledow et al., 2011).

\section{Procedure}

Before this study, we ensured that all measures were in line with the Chinese national research committee's ethical standards and the Helsinki declaration. We obtained consent from the participants included in the study. It comprised of the following elements: the 
purpose of the study, a statement regarding confidentiality and anonymity of participants, and a statement regarding the participant's right to withdraw their consent at any time. The survey takers were also requested to provide their demographic information.

An online survey was submitted to all the respondents but focused on the study criteria as those employees who had been employed at their current workplace for at least three months and worked at least forty hours a week (full-time employees). In the end, 32 members did not meet the sample selection criteria, leaving a sample of two hundred and thirty-seven participants. Of the 237 participants, sixty-eight percent were male; they had a mean age of 29.80 years $(S D=0.47)$ with an average tenure of 4.83 years $(S D=0.82)$.

\section{Data Analysis}

To test the proposed hypotheses, we first utilized SPSS version 23.0 to perform the hierarchical multiple regression to examine the mediating effect of negative affect on the proposed independent variables and work engagement. Then we examined the moderating effect of time pressure using hierarchical multiple regression. We first entered the control variables in Step 1, the independent variable in step 2, and the moderator in step 3. We mean-cantered all the component variables required to create the interaction term, i.e., role conflict (R.C.) and time pressure (T.P.). We then entered the interaction term (R.C. x T.P.) in step 4.

\section{Results}

The mean, standard deviation, and correlation for all variables are summarized in Table 1. Role conflict was observed to be positively related to negative affect $(\beta=0.17, p<0.05$, and negatively related to work engagement $(\beta=-0.16, p<0.05)$. Time pressure was positively related to negative affect $(\beta=0.21, p<0.05)$, and work engagement $(\beta=0.16, p<0.05)$. Further, negative affect was positively associated with work engagement $(\beta=0.17, p<0.05)$. Also, negative affect partially mediated the relationship between role conflict and work engagement $(\beta=0.33, p<0.05$; Table $2 a$, Model 6$)$ and fully mediated the relationship between time pressure and work engagement $(\beta=0.17, p<0.05$; Table 2b, Model 6$)$. Table 3 shows that the interaction between role conflict and time pressure was negatively correlated with negative employee affect $(\beta=-0.09, p<0.05)$. These depictions support hypotheses 1,2 , 3 , and 4 .

\section{Discussion}

The current study builds upon prior work (Breevaart \& Bakker, 2018) to examine the interactive effect of role conflict (a hindrance stressor) and time pressure (a challenge stressor) on work engagement via employee negative affect. Our results revealed that role conflict negatively predicted work engagement, and negative affect fully mediated the relationship. These findings are associated with preceding studies examining the detrimental effects of hindrance stressors (Kronenwett \& Rigotti, 2020). The findings can be explained by Dawson et al.'s (2016) assertion that employees' perceptions of a stressor as a hindrance trigger negative affect as it is considered a strain on their resources. In line with the challenge stressor- hindrance stressor framework Charkhabi (2019), we found the relationship between 
role conflict, negative affect, and employee work engagement relied on their time pressure. In particular, the results suggest that when employees have tight deadlines, they are likely to perceive role conflict as an opportunity to learn other skills, boosting their affect and enabling them to be engaged in the work. This finding implies that role conflict and time pressure interact to play an essential role in how employees regulate their moods, which reframes the employee's perception of role conflict as an opportunity to learn and demonstrate competence (i.e., become challenging). As employee perceptions of occupational stressors influence employee work engagement (Breevaart \& Bakker, 2018), these findings make an essential contribution to the literature, enabling us to understand better how such interaction influenced work engagement.

\section{Theoretical Implications}

This study made three notable theoretical contributions. The study measured the differences in time pressure and role conflict for within-person variation in negative affect during these stressors' appraisal. In line with previous results (Tadić et al., 2015), the perception of occupational stressors as either a challenge or a hindrance varied from person to person. This finding explained the inconsistent relationships between occupational stressors and fluctuation in affect in the literature.

Secondly, the study distinguished time pressure (challenge stressor) and role conflict (hindrance stressor), depending on the employee appraisal (Bennett et al., 2018; Stiglbauer \& Zuber, 2018). This distinction allowed us to examine specific stressors (i.e., role conflict and time pressure) instead of combining them in one broad category.

The study of challenge stressor- hindrance stressor framework showed that individuals working under time pressure are likely to overcome the strain imposed by role conflict, thereby buffering its effect on negative affect (e.g., Baethge et al. 2019). Therefore, the study tested time pressure as a boundary condition and examined its buffering effect (Webster et al., 2011). His study revealed that employees engaged more in their work when they had high time pressure versus low. Working employees believe that once they can overcome the challenge related stressors, they will get rewards and benefits in terms of a job promotion, job performance, and future growth, so they will work very hard to adopt active strategies. On the contrary, it is not easy for individuals to overcome stressful outcomes caused by hindrance sources. It hinders the achievement of employees' career development and work goals, such as job insecurity, bureaucratic procedures, role conflict and ambiguity, organizational politics, etc. Therefore, employees will not get any rewards and benefits in a predictable future and then accept negative strategies such as leaving or retreating, which are harmful to their careers. In conclusion, it is highly recommended that managers promote a win-win outcome for both organizations and employees (Boswell et al., 2004).

\section{Limitations and Future Directions}

The study had several hindrances that provided opportunities for future research. First, as with any cross-sectional study, we could not make causal inferences based on the research results. For example, stress literature (Kim \& Beehr, 2019) suggests that individual 
motivation could distinguish occupational stressors and their influence on work engagement. Research has shown that the relationship between occupational stressors and the motivation to learn (in times of role conflict) is inconsistent. The leading causes of the inconsistencies in the overlap in constructs and processes related to occupational stressors and motivation (Baer \& Oldham, 2006; Vroom, 2003; Weiner, 1986; Wilson \& Britt, 2020; Muntz \& Dormann, 2020). This study provided an avenue for future research to integrate these constructs as well as unify the theories.

Second, the study variables were collected from the same source (i.e., the employee). While there may have been a bias from the same source, it did not influence the results. Therefore, we call for future experimental or longitudinal research to confirm the variables' proposed causal relationships by occupational stressors, negative affect, and work engagement.

Third, the study suggested that hindrance stressors, such as role conflict, had detrimental effects on employee well-being in general and work engagement. It also revealed that environmental factors might be managed to enhance motivation and perceptions. These findings varied among individuals, which would also be the case if the sample was done among individuals with different tenure and education levels. We posit that work engagement and perception of time pressure as a challenge may have been relatively higher for employees who were not pursuing an Executive MBA. Future research needs to explore employees' needs in organizations and use them as a foundation for organizational practice.

In conclusion, the finds of our study provided avenues for exploring the findings. Future research may find it useful to distinguish challenge stress from hindrance stress when research centers on the relationship between occupational stressors, negative affect, and work engagement. Future research should attempt to replicate our results in organizational settings.

\section{Funding}

We received funds for this study from the block grants provided by the Chinese Government Scholarship.

\section{Acknowledgments}

Our acknowledgments go to my supervisor from the Graduate School of Management at the University of Science and Technology of China, for his valuable suggestions and expertise in our study. We are also very grateful for our anonymous reviewer whose support helped us to improve this study.

\section{References}

Abbas, M., \& Raja, U. (2019). Challenge-Hindrance Stressors and Job Outcomes: the Moderating Role of Conscientiousness. Journal of Business and Psychology. https://doi.org/10.1007/s10869-018-9535-z

Baer, M., \& Oldham, G. R. (2006). The curvilinear relation between experienced creative time pressure and creativity: Moderating effects of openness to experience and support for creativity. Journal of Applied Psychology, 91(4), 963-970. 
https://doi.org/10.1037/0021-9010.91.4.963

Baethge, A., Deci, N., Dettmers, J., \& Rigotti, T. (2019). Some days won't end ever": Working faster and longer as a boundary condition for challenge versus hindrance effects of time pressure. Journal of Occupational Health Psychology. https://doi.org/10.1037/ocp0000121

Bakker, A. B., \& Demerouti, E. (2007). The Job Demands-Resources model: state of the art. Journal of Managerial Psychology, 22(3), 309-328. https://doi.org/10.1108/02683940710733115

Bakker, A. B., Schaufeli, W. B., Leiter, M. P., \& Taris, T. W. (2008). Work engagement: An emerging concept in occupational health psychology. Work and Stress. https://doi.org/10.1080/02678370802393649

Bennett, A. A., Bakker, A. B., \& Field, J. G. (2018). Recovery from work-related effort: A meta-analysis. Journal of Organizational Behavior, 39(3), 262-275. https://doi.org/10.1002/job.2217

Bledow, R., Schmitt, A., Frese, M., \& Kühnel, J. (2011). The affective shift model of work engagement. Journal of Applied Psychology. https://doi.org/10.1037/a0024532

Boswell, W. R., Olson-Buchanan, J. B., \& LePine, M. A. (2004). Relations between stress and work outcomes: The role of the felt challenge, job control, and psychological strain. Journal of Vocational Behavior. https://doi.org/10.1016/S0001-8791(03)00049-6

Breevaart, K., \& Bakker, A. B. (2018). Daily job demands and employee work engagement: The role of daily transformational leadership behavior. Journal of Occupational Health Psychology, 23(3), 338-349. https://doi.org/10.1037/ocp0000082

Cavanaugh, M. A., Boswell, W. R., Roehling, M. V., \& Boudreau, J. W. (2000). An empirical examination of self-reported work stress among U.S. managers. Journal of Applied Psychology, 85(1), 65-74. https://doi.org/10.1037/0021-9010.85.1.65

Charkhabi, M. (2019). Quantitative job insecurity and well-being: Testing the mediating role of hindrance and challenge appraisals. Frontiers in Psychology. https://doi.org/10.3389/fpsyg.2018.02776

Davenport, H. T. (2005). Thinking for a living; How to get betterpPerformance and results from knowledge workers. Economist, 378(8461), 9-14. https://doi.org/10.1515/9783110289671

Dawson, K. M., O’Brien, K. E., \& Beehr, T. A. (2016). The role of hindrance stressors in the job demand-control-support model of occupational stress: A proposed theory revision. Journal of Organizational Behavior. https://doi.org/10.1002/job.2049

Deng, X., Ding, X., Cheng, C., \& Chou, H. M. (2016). Feeling Happy and Sad at the Same Time? Subcultural Differences in Experiencing Mixed Emotions between Han Chinese and Mongolian Chinese. Frontiers in Psychology, 7. https://doi.org/10.3389/fpsyg.2016.01692 
Extremera, N., \& Rey, L. (2016). Ability emotional intelligence and life satisfaction: Positive and negative affect as mediators. Personality and Individual Differences, 102, 98-101. https://doi.org/10.1016/j.paid.2016.06.051

Gerich, J. (2017). The relevance of challenge and hindrance appraisals of working conditions for employees' health. International Journal of Stress Management. https://doi.org/10.1037/str0000038

Greenhaus, J. H., \& Powell, G. N. (2006). When work and family are allies: A theory of work-family enrichment. In Academy of Management Review. https://doi.org/10.5465/amr.2006.19379625

Kim, M., \& Beehr, T. A. (2018). Challenge and hindrance demands lead to employees' health and behaviours through intrinsic motivation. Stress and Health. https://doi.org/10.1002/smi.2796

Kim, M., \& Beehr, T. A. (2019). Thriving on Demand: Challenging Work Results in Employee Flourishing Through Appraisals and Resources. International Journal of Stress Management. https://doi.org/10.1037/str0000135

Kronenwett, M., \& Rigotti, T. (2020). All's well that ends well!? Moderating effects of goal progress on the relation between challenge and hindrance appraisal and well-being. Journal of Managerial Psychology. https://doi.org/10.1108/JMP-11-2019-0618

Lazarus, R. S. (1991). Cognition and motivation in emotion. American Psychologist, 46(4), $352-367$.

Lepine, J. A., Lepine, M. A., \& Jackson, C. L. (2004). Challenge and hindrance stress: Relationships with exhaustion, motivation to learn, and learning performance. In Journal of Applied Psychology. https://doi.org/10.1037/0021-9010.89.5.883

Lin, C. P., Xian, J., Li, B., \& Huang, H. (2020). Transformational Leadership and Employees' Thriving at Work: The Mediating Roles of Challenge-Hindrance Stressors. Frontiers in Psychology. https://doi.org/10.3389/fpsyg.2020.01400

Mazzola, J. J., \& Disselhorst, R. (2019). Should we be "challenging" employees?: A critical review and meta-analysis of the challenge-hindrance model of stress. Journal of Organizational Behavior, 40(8), 949-961. https://doi.org/10.1002/job.2412

McGrath, J. E., \& Beehr, T. A. (1990). Time and the stress process: Some temporal issues in the conceptualization and measurement of stress. Stress Medicine, 6(2), 93-104. https://doi.org/10.1002/smi.2460060205

Monin, B., Sawyer, P. J., \& Marquez, M. J. (2008). The rejection of moral rebels: Resenting those who do the right thing. Journal of Personality and Social Psychology, 95(1), 76-93. https://doi.org/10.1037/0022-3514.95.1.76

Muntz, J., \& Dormann, C. (2020). Moderating effects of appreciation on relationships between illegitimate tasks and intrinsic motivation: a two-wave shortitudinal study. European 
Journal

of

Work

and

Organizational

Psychology.

https://doi.org/10.1080/1359432X.2019.1706489

Nahrgang, J. D., Morgeson, F. P., \& Hofmann, D. A. (2011). Safety at work: A meta-analytic investigation of the link between job demands, job resources, burnout, engagement, and safety outcomes. Journal of Applied Psychology, 96(1), 71-94. https://doi.org/10.1037/a0021484

O’Brien, K. E., \& Beehr, T. A. (2019). So far, so good: Up to now, the challenge-hindrance framework describes a practical and accurate distinction. Journal of Organizational Behavior, 40(8), 962-972. https://doi.org/10.1002/job.2405

Olafsen, A. H., \& Frølund, C. W. (2018). Challenge accepted! Distinguishing between challenge- and hindrance demands. Journal of Managerial Psychology. https://doi.org/10.1108/JMP-04-2017-0143

Parker, S. K., Morgeson, F. P., \& Johns, G. (2017). One hundred years of work design research: Looking back and looking forward. Journal of Applied Psychology, 102(3), 403-420. https://doi.org/10.1037/ap10000106

Perrewe, P. L., Zellars, K. L., Ferris, G. R., Rossi, A. M., Kacmar, C. J., \& Ralston, D. A. (2004). Neutralizing job stressors: political skill as an antidote to the dysfunctional consequences of role conflict. Academy of Management Journal, 47(1), 141-152. https://doi.org/10.2307/20159566

Prem, R., Ohly, S., Kubicek, B., \& Korunka, C. (2017). Thriving on challenge stressors? Exploring time pressure and learning demands as antecedents of thriving at work. Journal of Organizational Behavior, 38(1), 108-123. https://doi.org/10.1002/job.2115

Rosen, C. C., Dimotakis, N., Cole, M. S., Taylor, S. G., Simon, L. S., Smith, T. A., \& Reina, C. S. (2020). When challenges hinder: An investigation of when and how challenge stressors impact employee outcomes. Journal of Applied Psychology. https://doi.org/10.1037/ap10000483

Schaufeli, W., Salanova, M., González-romá, V., \& Bakker, A. (2002). The Measurement of Engagement and Burnout: A Two Sample Confirmatory Factor Analytic Approach. Journal of Happiness Studies. https://doi.org/10.1023/A:1015630930326

Schmitt, A., Ohly, S., \& Kleespies, N. (2015). Time pressure promotes work engagement. Journal of Personnel Psychology, 14(1), 28-36.

Schwarz, N., \& Clore, G. L. (2006). Feelings and Phenomenal Experiences. In Social Psychology. Handbook of basic principles.

Sonnentag, S. (2003). Recovery, work engagement, and proactive behavior: A new look at the interface between nonwork and work. Journal of Applied Psychology. https://doi.org/10.1037/0021-9010.88.3.518

Sonnentag, S. (2018). The recovery paradox: Portraying the complex interplay between job 
stressors, lack of recovery, and poor well-being. Research in Organizational Behavior, 38, 169-185. https://doi.org/10.1016/j.riob.2018.11.002

Sonnentag, S., \& Zijlstra, F. R. H. (2006). Job characteristics and off-job activities as predictors of need for recovery, well-being, and fatigue. Journal of Applied Psychology, 91(2), 330-350. https://doi.org/10.1037/0021-9010.91.2.330

Steed, L. B., Swider, B. W., Keem, S., \& Liu, J. T. (2019). Leaving Work at Work: A Meta-Analysis on Employee Recovery From Work. Journal of Management. https://doi.org/10.1177/0149206319864153

Stiglbauer, B., \& Zuber, J. (2018). Challenge and hindrance stress among schoolteachers. Psychology in the Schools, 55(6), 707-721. https://doi.org/10.1002/pits.22135

Tadić, M., Bakker, A. B., \& Oerlemans, W. G. M. (2015). Challenge versus hindrance job demands and well-being: A diary study on the moderating role of job resources. Journal of Occupational and Organizational Psychology, 88(4), 702-725. https://doi.org/10.1111/joop.12094

Vroom, V. H. (2003). Educating managers for decision making and leadership. Management Decision, 41(10), 968-978. https://doi.org/10.1108/00251740310509490

Webster, J. R., Beehr, T. A., \& Love, K. (2011). Extending the challenge-hindrance model of occupational stress: The role of appraisal. Journal of Vocational Behavior, 79(2), 505-516. https://doi.org/10.1016/j.jvb.2011.02.001

Weiner, B. (1986). Attribution, emotion, and action. In Handbook of motivation and cognition: Foundations of social behavior, volume 1.

Wilson, C. A., \& Britt, T. W. (2020). Living to work: The role of occupational calling in response to challenge and hindrance stressors. Work and Stress. https://doi.org/10.1080/02678373.2020.1743791

Wu, H., Qiu, S., Dooley, L. M., \& Ma, C. (2019). The Relationship between Challenge and Hindrance Stressors and Emotional Exhaustion: The Moderating Role of Perceived Servant Leadership. International Journal of Environmental Research and Public Health, 17(1), 282. https://doi.org/10.3390/ijerph17010282

\section{Appendix}

Table 1. Mean, standard deviations, correlation, and reliability analysis

\begin{tabular}{lrrrrrrrrr}
\hline & $\boldsymbol{M}$ & $\boldsymbol{S D}$ & $\mathbf{1}$ & $\mathbf{2}$ & $\mathbf{3}$ & $\mathbf{4}$ & $\mathbf{5}$ & $\mathbf{6}$ & $\mathbf{7}$ \\
\hline 1. Gender & 1.32 & .46 & 1 & & & & & & \\
2. Age & 1.16 & .47 & -.03 & 1 & & & & & \\
3. Tenure & 2.07 & .82 & .02 & $.29^{* *}$ & 1 & & & & \\
4. Work engagement & 3.88 & 1.75 & .12 & .00 & .00 & $(\mathbf{0 . 9 5})$ & & & \\
5. Negative affect & 3.29 & 1.06 & .06 & -.02 & .02 & $.17^{*}$ & $(\mathbf{0 . 8 5})$ & & \\
6. Time pressure & 3.72 & 1.49 & -.01 & .01 & $.20^{* *}$ & $.16^{*}$ & $.21^{*}$ & $(\mathbf{0 . 9 0 )}$ & \\
7. Role conflict & 3.21 & 1.26 & .05 & .04 & $.22^{* *}$ & $-.16^{*}$ & $.17^{*}$ & $.19^{*}$ & $(\mathbf{0 . 8 8})$ \\
\hline
\end{tabular}

Notes: $\mathrm{N}=237$.

$* \mathrm{p}<0.05 ; \quad * * \mathrm{p}<0.01$. 
Table 2 a. Negative affect as a mediator of role conflict and work engagement

\begin{tabular}{|c|c|c|c|c|c|c|c|c|c|c|c|c|}
\hline & & gative Aff & & & & & & & Work & engagement & & \\
\hline & Model 1 & Model 2 & $\begin{array}{l}\text { L.L. } \\
\text { C. I }\end{array}$ & $\begin{array}{l}\text { UL } \\
\text { C. I }\end{array}$ & Model 3 & Model 4 & $\begin{array}{l}\text { L.L. } \\
\text { C. I }\end{array}$ & $\begin{array}{l}\text { UL } \\
\text { C. I }\end{array}$ & Model 5 & Model 6 & $\begin{array}{l}\text { L.L. } \\
\text { C. I }\end{array}$ & $\begin{array}{l}\text { U.L. } \\
\text { C. I }\end{array}$ \\
\hline 1. Gender & $.13(.19)$ & $.12(.19)$ & -.26 & .50 & $.46(.32)$ & $.49(.31)$ & -.13 & 1.13 & $.46(.32)$ & $.45(.31)$ & -.16 & 1.08 \\
\hline 2. Age & $-.07(.20)$ & $-.07(.20)$ & -.46 & .32 & $.01(.33)$ & $.00(.33)$ & -.65 & .65 & $.01(.33)$ & $.02(.32)$ & -.61 & .66 \\
\hline 3. Employment & $.04(.11)$ & $-.00(.11)$ & -.24 & .22 & $-.00(.19)$ & .08 (.19) & -.29 & .47 & $-.00(.19)$ & .09 (.19) & -.28 & .46 \\
\hline 4. Role conflict & & $\begin{array}{r}.14(.07) \\
*\end{array}$ & .00 & .29 & & $-.25(.12) *$ & -.49 & -.01 & & $\begin{array}{r}-.30(.12) \\
*\end{array}$ & -.54 & -.06 \\
\hline 5. Negative affect & & & & & & & & & & $.33(.14) *$ & .05 & .60 \\
\hline
\end{tabular}

Table $2 \mathrm{~b}$. Negative affect as a mediator of time pressure and work engagement

\begin{tabular}{|c|c|c|c|c|c|c|c|c|c|c|c|c|}
\hline & \multicolumn{4}{|c|}{ Negative Affect } & \multirow[b]{2}{*}{ Model 3} & \multirow[b]{2}{*}{ Model 4} & \multirow[b]{2}{*}{$\begin{array}{l}\text { L.L. } \\
\text { C. I }\end{array}$} & \multicolumn{5}{|c|}{ Work engagement } \\
\hline & Model 1 & Model 2 & $\begin{array}{l}\text { L.L. } \\
\text { C. I }\end{array}$ & $\begin{array}{l}\text { UL } \\
\text { C. I }\end{array}$ & & & & $\begin{array}{c}\text { UL } \\
\text { C. I }\end{array}$ & Model 5 & Model 6 & $\begin{array}{l}\text { L.L. } \\
\text { C. I }\end{array}$ & $\begin{array}{l}\text { U.L. } \\
\text { C. I }\end{array}$ \\
\hline 1. Gender & $.13(.19)$ & $.14(.19)$ & -.23 & .53 & $.46(.32)$ & $.47(.31)$ & -.15 & 1.11 & $.46(.32)$ & $.44(.31)$ & -.18 & 1.07 \\
\hline 2. Age & $-.07(.20)$ & $-.05(.20)$ & -.44 & .34 & $.01(.33)$ & $.04(.33)$ & -.60 & .70 & $.01(.33)$ & $.06(.32)$ & -.59 & .71 \\
\hline 3. Employment & $.04(.11)$ & $-.02(.11)$ & -.25 & .21 & $-.00(.19)$ & $-.08(.19)$ & -.46 & .29 & $-.00(.19)$ & $-.08(.19)$ & -.46 & .30 \\
\hline 4. Time pressure & & $.15(.06)^{*}$ & .03 & .28 & & $.20(.10) *$ & .00 & .41 & & $.21(.14)$ & -.06 & .50 \\
\hline 5. Negative affect & & & & & & & & & & $.17(.10) *$ & -.03 & .37 \\
\hline $\mathrm{R}^{2}$ & .006 & .053 & & & .015 & .015 & & & .015 & .015 & & \\
\hline$\Delta \mathrm{R}^{2}$ & .006 & $.048 *$ & & & $.048 *$ & $.032 *$ & & & $.062 *$ & $.042 *$ & & \\
\hline
\end{tabular}

Notes: $\mathrm{N}=237$.

$* \mathrm{p}<0.05 ; * * \mathrm{p}<0.01 ; * * * \mathrm{p}<0.001$

Table 3. Results of the Moderating Effect of Time Pressure

\begin{tabular}{|c|c|c|c|c|c|}
\hline & \multirow[b]{2}{*}{ Model 1} & \multicolumn{4}{|c|}{ Negative Affect } \\
\hline & & Model 2 & Model 3 & $\begin{array}{l}\text { L.L. } \\
\text { C. I }\end{array}$ & $\begin{array}{l}\text { U.L. } \\
\text { C. I }\end{array}$ \\
\hline 1. Gender & $.13(.19)$ & $.14(.19)$ & $.07(.19)$ & -.30 & .45 \\
\hline 2. Age & $-.07(.20)$ & $-.05(.19)$ & $-.00(.19)$ & -.39 & .38 \\
\hline 3. Employment & $.04(.11)$ & $-.03(.12)$ & $-.04(.12)$ & -.28 & .19 \\
\hline 4. Time pressure (T.P.) & & $.01(.08)$ & $.00(.08)$ & -.15 & .16 \\
\hline 5. Roll conflict (R.C.) & & $\begin{array}{r}.17(.06) \\
* *\end{array}$ & $.14(.06) *$ & .02 & .27 \\
\hline C.S. x R.C. & & & $-.09(.04) *$ & -.19 & -.00 \\
\hline $\mathrm{R}^{2}$ & .006 & $.060 * *$ & $.095 * *$ & & \\
\hline$\Delta \mathrm{R}^{2}$ & .006 & $.065 * *$ & $.025 * *$ & & \\
\hline
\end{tabular}

Notes: $\mathrm{N}=237$.

$* \mathrm{p}<0.05 ; * * \mathrm{p}<0.01 ; * * * \mathrm{p}<0.001$ 


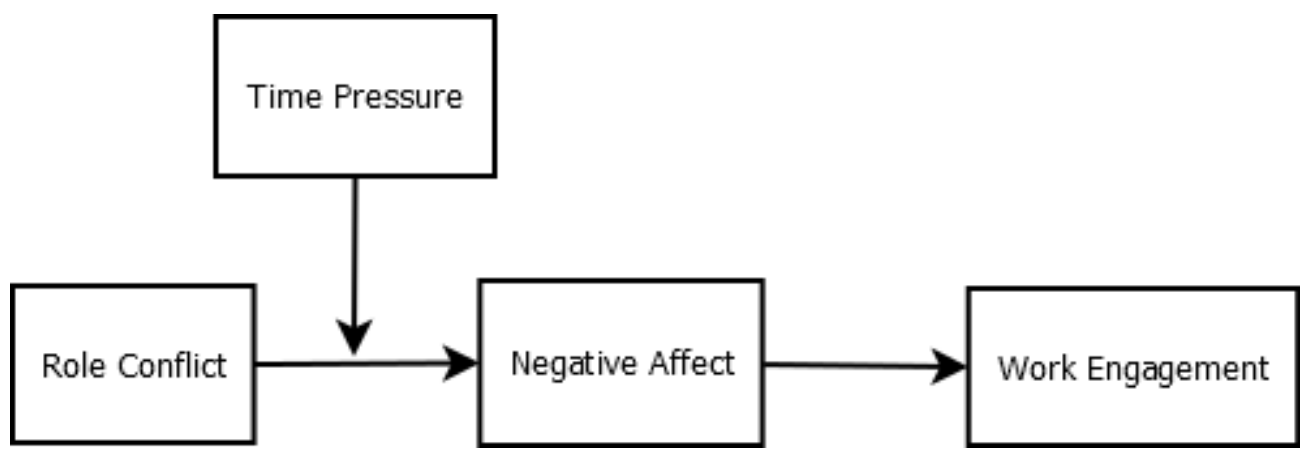

Figure 1. The hypothesized model

\section{Copyright Disclaimer}

Copyright for this article is retained by the author(s), with first publication rights granted to the journal.

This is an open-access article distributed under the terms and conditions of the Creative Commons Attribution license (http://creativecommons.org/licenses/by/4.0/). 